\title{
Investigation of The Effect of Different Prosthesis Designs and Numbers on Stress, Strain and Deformation Distribution
}

\author{
Gözde Nur Nişanci ${ }^{a}$, Yllmaz Güvercin $^{b}$, Sabit Melih Ateș ${ }^{c}$, Hasan Ölmez ${ }^{d}$, Ecren Uzun Yaylacı ${ }^{e}$, \\ Murat Yaylact ${ }^{f^{*}}$ \\ ${ }^{a, f^{*}}$ Recep Tayyip Erdogan University, Department of Civil Engineering, 53100, Rize, Turkey \\ ${ }^{b}$ Recep Tayyip Erdogan University, Department of Orthopaed \& Traumatol, 53100, Rize, Turkey \\ ${ }^{c}$ Recep Tayyip Erdogan University, Department of Prosthetic Dentistry, 53100, Rize, Turkey \\ ${ }^{d}$ Karadeniz Technical University, Department of Marine Engineering Operations, 61530, Trabzon, Turkey \\ ${ }^{e}$ Karadeniz Technical University, Surmene Faculty of Marine Science, 61530, Trabzon, Turkey \\ *E-mail address: gozdenurnisanci@hotmail.com ${ }^{\text {a }}$, yilmaz guvercin61@ hotmail.com ${ }^{\mathrm{b}}$, melih ates@, hotmail.com ${ }^{\mathrm{c}}$, \\ hasanolmez@ktu.edu.tr ${ }^{\mathrm{d}}$, ecrenuzun@,ktu.edu.tr ${ }^{\mathrm{e}}$, murat.yaylaci@erdogan.edu.tr \\ ORCID numbers of authors: \\ 0000-0002-1976-1948, 0000-0003-1861-2083 ${ }^{b}, 0000-0001-7137-2096^{c}, 0000-0001-5351-4046^{d}, 0000-0002-2558-2487^{e}$, \\ $0000-0003-0407-1685^{f^{*}}$
}

Received date: 25.10 .2020

Accepted date: 24.12 .2020

\begin{abstract}
Dental implant applications for edentulous jaws are today considered a predictable, safe, and daily technique for giving patients new aesthetics and function. However, the success of the implant therapy should be thoroughly investigated for long-term clinical results about the stress distribution in hosting bone tissue and prosthetic components. In this study, the effect of different prosthesis designs on the stress distribution around the abutment and dental implant in bone tissue was investigated using the finite element method (FEM) with Workbench module of the ANSYS package program. The examination focuses on the effect of the number of implants in teeth layouts on the distribution of stresses, strains, and displacements. In the study the historical development of dental implant problems is mentioned, and some previous studies are summarized. Critical information is also given about biomechanics, dental implants, jawbone, teeth, and the finite element method. Totally four different cases, one layout with three implants and three layouts with two implants, were analyzed. Titanium was used as an implant and abutment material. Nobel Active implants and abutments manufactured by Nobel BioCare Company were used for complete toothless lower jaw case. The critical stress, strain, and displacement values were determined for all four different scenarios. As a result, it was concluded that stresses, strains, and displacements have lower values for the design of triple dental implants compared to other layouts.
\end{abstract}

Keywords: Biomechanics, Dental implant, Finite element method

\section{Introduction}

Mechanical behaviors of designs that can keep up with the developing technology is one of the main topics of researchers. For this reason, researchers have made analytical and numerical solutions about the mechanical behavior of structures [1-8]. Biomechanics of the respiratory, skeletal, muscular and cardiovascular systems, soft and hard tissues, biological fluids, prosthetics, and tissue-implant interfaces are among the specialized topics of multidisciplinary numerical analysis. In this dental implant treatment process not realistically considering the importance of biomechanical effects may prevent them from continuing their task successfully for a long time and even lead to serious clinical complications. 
Dental implant treatments have rapidly increased since the evolution of osseointegration, replacing removable dentures in the treatment of partially edentulous patients. Regardless of the clinician's success, many factors play an important role in load transfer from dental implant to the surrounding bone, such; as loading type, bone-implant integration, length and diameter of the implants, implant surface characteristics, prosthesis design, and quality of the host bone [9]. In the literature, it seen that the relationship between the success or failure of an implant and its useful life with the bone-implant interface has been studied [10]. Factors affecting the balance of implants have been presented and the principles on which implants should be designed for long-term success have been emphasized [11].

In ancient times, it can be counted as a solution for using stone, wood, and animal teeth in the jaw bones instead of a tooth that was lost. Dental implants are the most needed of these kinds of materials and are applied to human jaws in line with the studies performed today. Dental implants are placed under the bony or mucous membrane of the rigid or movable prosthesis, inside the jawbone, to transmit the forces formed between the jaws to the joint points instead of the teeth lost for any reason. Biocompatible materials are used for its production.

Biomechanical behavior analysis are important implications for implants to do their job or not. Failure to apply the occlusal forces in accordance with the real scenarios in calculations poorly affects the stresses at the implant-prosthesis junction and the reshaping of the bone around the implant. Using biomechanical behaviors, which have a significant impact on the life of prostheseis, in this way enables the optimization of biomechanical conditions. There are several methods in the literature to examine stress, strains, and displacements for dental implant analysis. In experimental tests in laboratories, strain measurements give reliable results only at the specific position of the indicator. Photoelasticity provides realistic and reliable information about the global location of stresses, apart from the quantitative values. The finite element analysis is one of the most widely used methods in recent years, not only in the field of engineering but also in the field of dental implants, since it shows the problems that may occur before the application and shows the stresses that it will create around the implant. Geometric designs can be created using the finite element method. Material selection and geometric design are very important in determining the success of dental implants. The finite element analysis (FEA) can provide complete quantitative data at any local location of the model. Therefore, FEA has become a valuable analytical method for numerical analysis of implant applications. Studies on dental implant applications in different cases in the literature can be summarized as follows.

Van Oosterwyck et al. have examined the effects of bone-implant interface, bone mechanical properties, unicortical versus bicortical implant fixation and the presence of a lamina dura by using FEM [10]. Geng et al. have investigated the bone-implant interface, implant prosthesis connection, and its use in multiple implant prostheses [11]. Kunavisarut et al. have aimed to investigate the effect of dental implant-supported passive fit prostheses, cantilever prostheses and various occlusive forces on prostheses, implant components, and stress around the bone using FEM [12]. Ding et al. have aimed to create a 3D FE model of a mandible with dental implants to analyze the stress distribution in the bone around the implants for different diameters [13]. Hsu et al. have studied the application of the finite element analysis in dentistry [14]. Kumar et al. have investigated the stress distribution around implant and tooth the finite element method in implant- supported fixed prosthesis designs [15]. El-Anwar and El-Zawahry have studied 25 different 3D implant designs with a gradual increase in diameter and length in order to extract simplified design equations to better understand implants behavior, using the finite element method [16]. Baggi et al. have compared two different restorative techniques for 
complete-arch rehabilitations supported by four implants. [17]. Liu et al. have aimed to evaluate the tension distribution in the peripheral bone, the tension in the abutments and the tension in the abutments, and the prosthetic stability of the mandibular overpressures attached with different implants under different loading conditions [18]. Cicciu et al. has studied the FEM evaluation of cement and screw-held dental implants against a single-tooth crown prosthesis [19]. Hambli has developed a simple and reliable FE model coupled to quasi-brittle damage law to describe the multiple cracks initiation [20]. Parkhe et al. have performed a finite element analysis to determine the best thread shape by comparing stress-induced in cortical and cancellous bone [21]. Gonzalez and Nuno have characterized the three types of manufacturing irregularities on an additive manufactured porous titanium sample having a simple cubic unitcell using FEA [22]. Mahajan and Patil have studied the optimization of dental implants using FEA [23]. Rzaghi et al. have studied dynamic simulation and the finite element analysis of the maxillary bone injury around the dental implants for different chewing loads [24]. Demenko et al. have estimated implant success prognosis, considering $0.2 \mathrm{~mm}$ annual bone loss for successful implantation [25]. Macedo et al. have evaluated the stresses and bone volume of an external hexagon or Morse taper dental implant systems by FEA [26]. Aumnakmanee et al. have studied the effects of four different Thread designs of dental implant prosthetics on stress at four different areas [27]. Jafarian et al. have studied the stress distribution around the implants of different lengths and diameters with the finite element analysis [28]. Wu et al. have evaluated the all-on-four treatment with four osseointegrated implants in terms of the biomechanical effects of implant design and loading position on the implant and surrounding bone using both test results and 3D FEA [29]. Jiménez et al. have used the FEA to determine whether the risks linked to Narrow-diameter implants (NDIs) could be mitigated by the mechanical advantages [30]. Robau Porrua et al. have examined the effect of the diameter, length, elasticity module on a dental implant on the stress and strain distribution in the implant bone by 3D FEA [31]. Zhong et al. have analyzed the biomechanical responses of zirconiabased FAFDPs with different implant configurations by using the FEM [32]. The effect of different abutment materials on the stress distribution in bone tissue around the dental implant has investigated using the FEM by Terzi et al. [33].

Biomechanical principles help to evaluate existing designs in dental implantology and to model new designs. The FEM has been adapted from the engineering field to the dental implantology for an approximate prediction and evaluation of the amount of stress that will occur on the implant or surrounding tissues during the function performed. The finite element method is a method that explains the complex biomechanics of the implant studied and provided numerical results. In this study, it was aimed to find the stress, strain, and displacement values of the dental implants with different geometrical structures by changing the number of implants in four different strategies.

\section{Finite Element Analysis}

In this section, a $3.9 \mathrm{~mm}$ diameter prosthesis system is designed on bone tissue taken from a healthy person and this prosthesis is mounted. The geometry of the underlying system is introduced. The prosthesis and abutment system designed on the obtained bone tissue is connected under the first minor molar-second minor molar and first major molar teeth. Solidworks program was used to create the geometry [34]. After the design of the 3D model, the FEM was used for analysis. Stress, strain and displacement values were compared on the model by changing the selected material on the same model. In this study, the ANSYS Workbench program was used for the finite element analysis [35]. 
The first step to be taken when starting the finite element analysis is to create a threedimensional model of the object to be worked on. While preparing these models, different imaging methods can be used depending on the complexity of the object. Computerized tomography and magnetic resonance imaging methods are two examples. While transferring such images to the computer environment and creating the model, firstly real models are created by scanning each detail of the object with $3 \mathrm{D}$ scanners and transferred to the computer environment or drawn by the researcher with three-dimensional modeling programs. The desired results can be simulated through the mathematical model and test simulations can be repeated at any time. Therefore, a well-tested and validated mathematical model offers researchers a very powerful tool for analysis.

The geometric model prepared in the finite element analysis is divided into simple geometric infrastructures called elements, which are classified according to certain features. As some example of these features, geometric shape (triangle, parallel edge, quadrilateral), size (onedimensional, two-dimensional, three-dimensional) and the number of nodes can be given. Element types are shown in Figure 1. These elements are fully compatible with the geometry of the existing main structure. They show the desired mechanical properties in each region of the main structure.

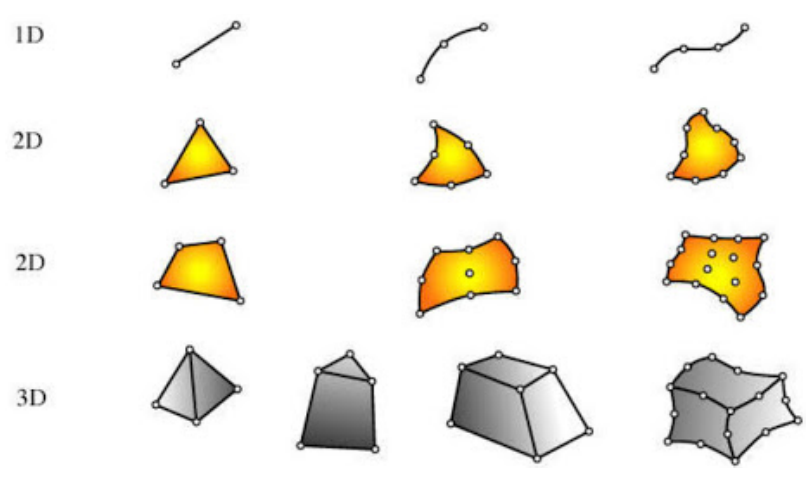

Fig. 1. Finite element types (one-dimensional, two-dimensional and three-dimensional)

After the desired model is transferred to the computer environment, the division of the elements is called the creation of a network structure. The model analysis can be made in the most realistic way and reduced to a simpler model. Corner contact points between the elements are called knot points. In the second step, material data such as elasticity modulus, Poisson ratio used material are defined in the program. The boundary conditions of the object and the forces applied to the object are defined in the third step of the analysis. After entering this information, the analysis is performed by adjusting the direction, intensity and angle of the force for the loading conditions to be applied to the object. As a result of the solution, the sub-elements of each object and the entire structure are evaluated. In the interpretation of the analysis made using the finite element method, the values that directly affect the results of the analysis are chosen. These are, the geometry of the bone and implant, material properties, boundary conditions, force properties, and properties of the implant-bone interface.

In this study, the finite element analysis was performed by transferring dental implant, abutment and lower jawbone modeling from Solidworks to the ANSYS Workbench program. The computerized tomography image of the bone tissue simplified and modeled to the desired extent is shown in Figure 2. 


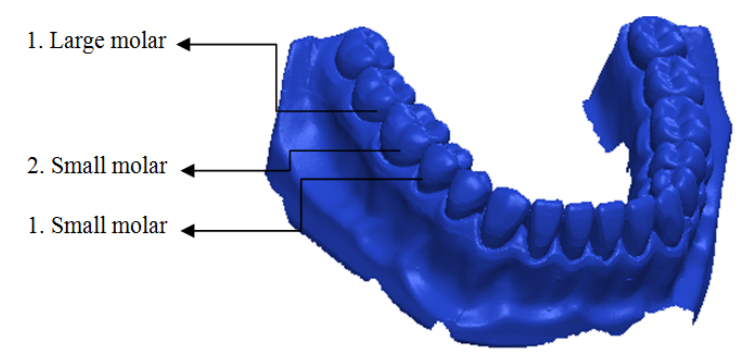

Fig. 2. Created solid modeling of the prosthesis

The bone tissue image obtained by computerized tomography has been reduced to a simpler model by Solidworks program. As seen in Figure 3-b, the $3.9 \mathrm{~mm}$ diameter and $13 \mathrm{~mm}$ length dental implant of the Nobel Biocare Company named the Nobel Active which provides excellent stability in all areas was created by the Solidworks program. In Figure 3-c, a suitable custom abutment (personalized application) designed according to the dental implant solid model is shown in Figure 3.
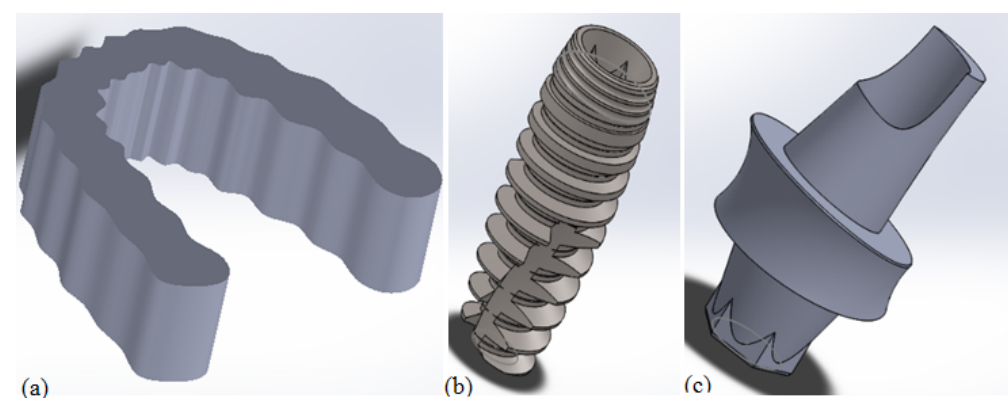

Fig. 3. (a) Bone modeling (b) Dental implant modeling (c) Abutment modeling

Layouts have been created for assembly operations and listed as follows in Figure 4. In this section, different geometrical assemblies of prosthetic systems designed with a diameter of 3.9 $\mathrm{mm}$ and abutment systems of which the assemblies made are described. Prosthesis and abutment systems designed on the resulting bone tissue are linked under teeth as the following designs; Model 1: 1. small molar, 2. small molar, and 1. large molar

Model 2: 1. small molar, and 1. large molar

Model 3: 1. small molar, and 2. small molar

Model 4: 2. small molar, and 1. large molar

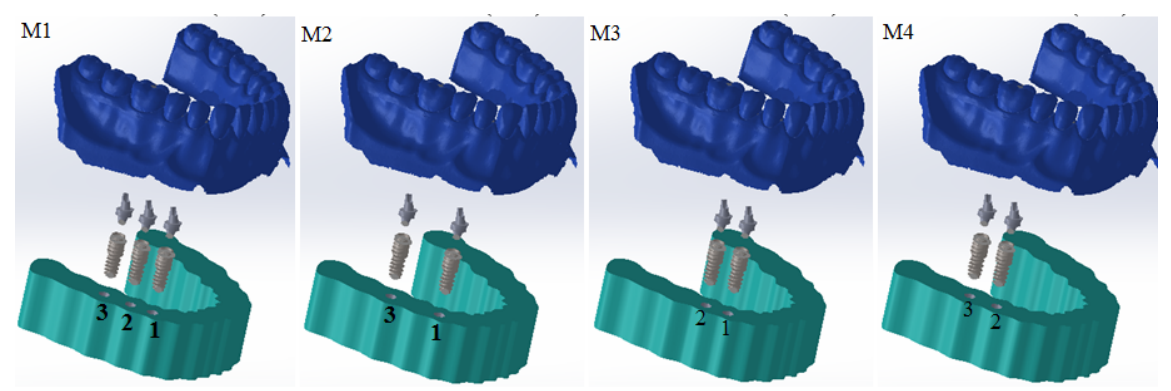

Fig. 4. Assembly layouts

After the solid model of each part were created, they were transferred to the assembly stage. Bone, dental implants and abutments are combined by placing them in suitable positions for assembly. Firstly, the mandible and dental implants were created in the SolidWorks software and then transferred to the ANSYS Workbench program for the analysis, as shown in Figure 5. 


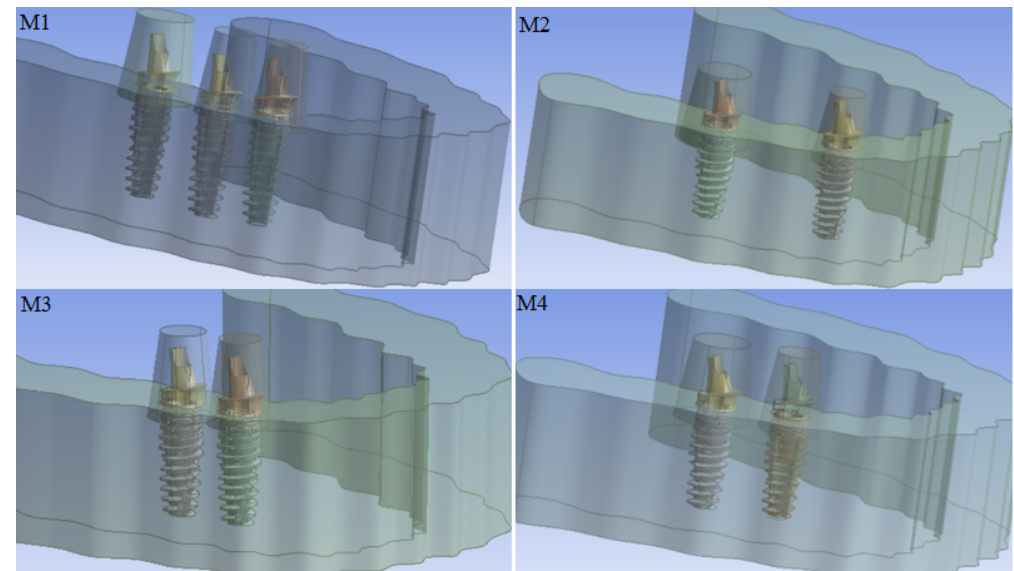

Fig. 5. Imported geometry for ANSYS Workbench

The solid model was transferred to the ANSYS Workbench program for numerical solution. The data that must be entered into the system to perform the analysis are introduced one by one. Young's modulus and Poisson ratios are taken from the literature. The data used in the study are shown in Table 1.

Table 1. The material properties of the models

\begin{tabular}{llccc}
\hline & Materials & $\begin{array}{c}\text { Modulus of elasticity } \\
(\mathrm{MPa})\end{array}$ & $\begin{array}{c}\text { Poisson's } \\
\text { ratio }\end{array}$ & Literature \\
\hline Abutment & Ti6A14V & 113800 & 0.34 & {$[36]$} \\
Implant & Ti6A14V & 113800 & 0.34 & {$[36]$} \\
Bone & Bone & 14000 & 0.30 & {$[37]$} \\
\hline
\end{tabular}

In Figures 6-7, the mesh structure of the solid model on ANSYS Workbench is given. 191622 elements and 321422 nodes are used in the model. After the mesh structure was created, $50 \mathrm{~N}$ load was applied to the abutments.
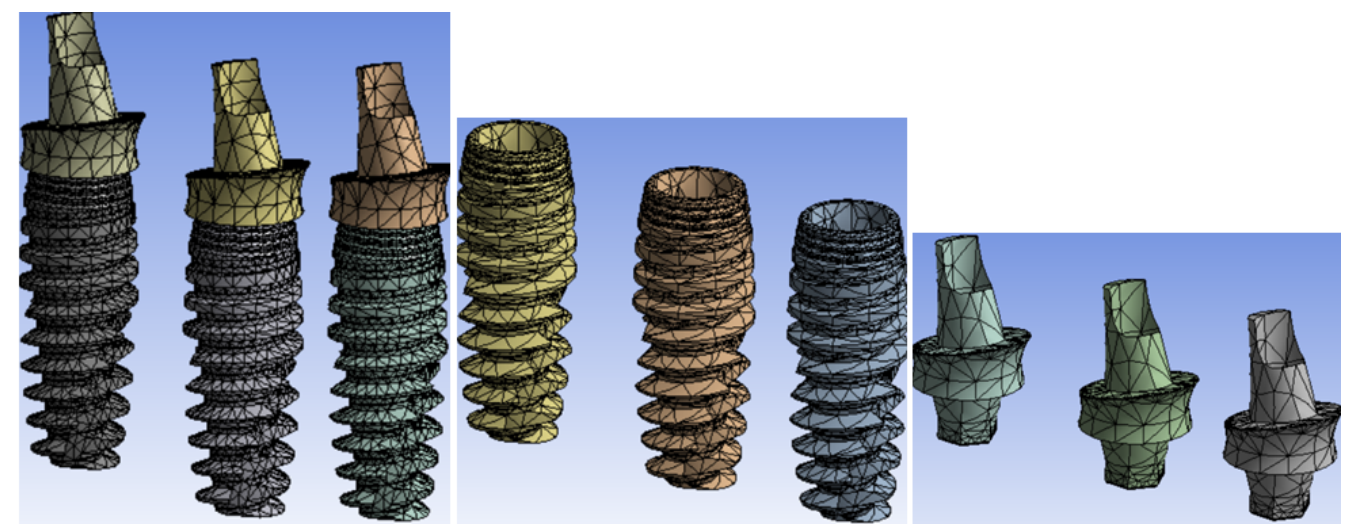

Fig. 6. 3D mesh of the dental implant and abutment 


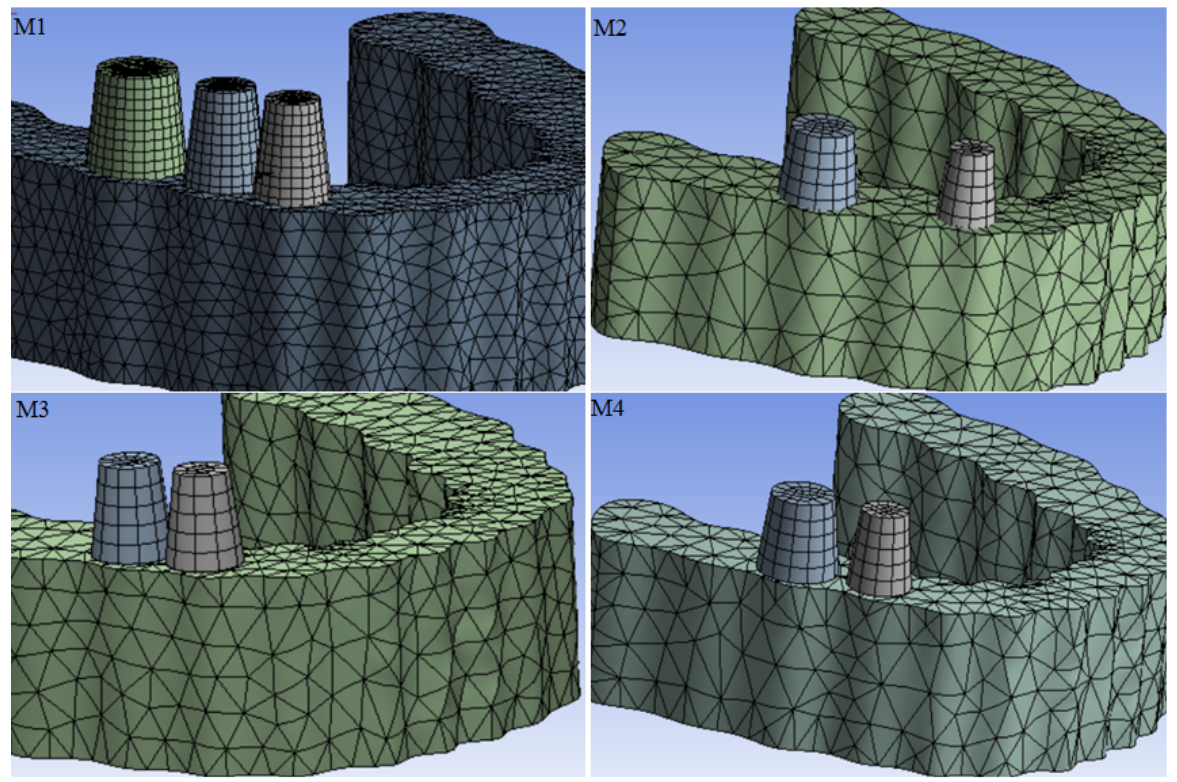

Fig. 7. 3D mesh of the structure

Three different models with two implants and one model with three implants were created. Three different teeth were applied to the models, namely the first molars, the second molars and the third molars. Titanium was chosen and used as a dental implant material. Static structural stress analysis was performed for the models. After all the necessary data such as boundary conditions and loads are defined in the ANSYS Workbench software, the analysis phase has been started and the obtained results are described in the numerical results part. Results of four different models under $50 \mathrm{~N}$ load are given below.

\section{Numerical Results}

In this study, the finite element method was used to obtain stress, strain, and deformation values in each region of the bone, dental implant, and abutment. Titanium was used as a dental implant, and abutment material for all models. The stress, strain, and displacement images and numerical values of the analysis results for the Model 1 (M1), Model 2 (M2), Model 3 (M3), and Model 4 (M4) are shown in Figures 8-10 and Tables 2-5, respectively.

The stress, strain, and displacement images and numerical values of the analysis results for the bone are shown in Figure 8 and Table 2, respectively. As can be seen from the table, the highest stress values were obtained in the M2, the highest strain values were obtained in the M4, and the highest deformation values were obtained in the M3. The lowest stress values were obtained in the M1, the lowest strain values were obtained in the M1 and the lowest deformation values were obtained in the M2. 


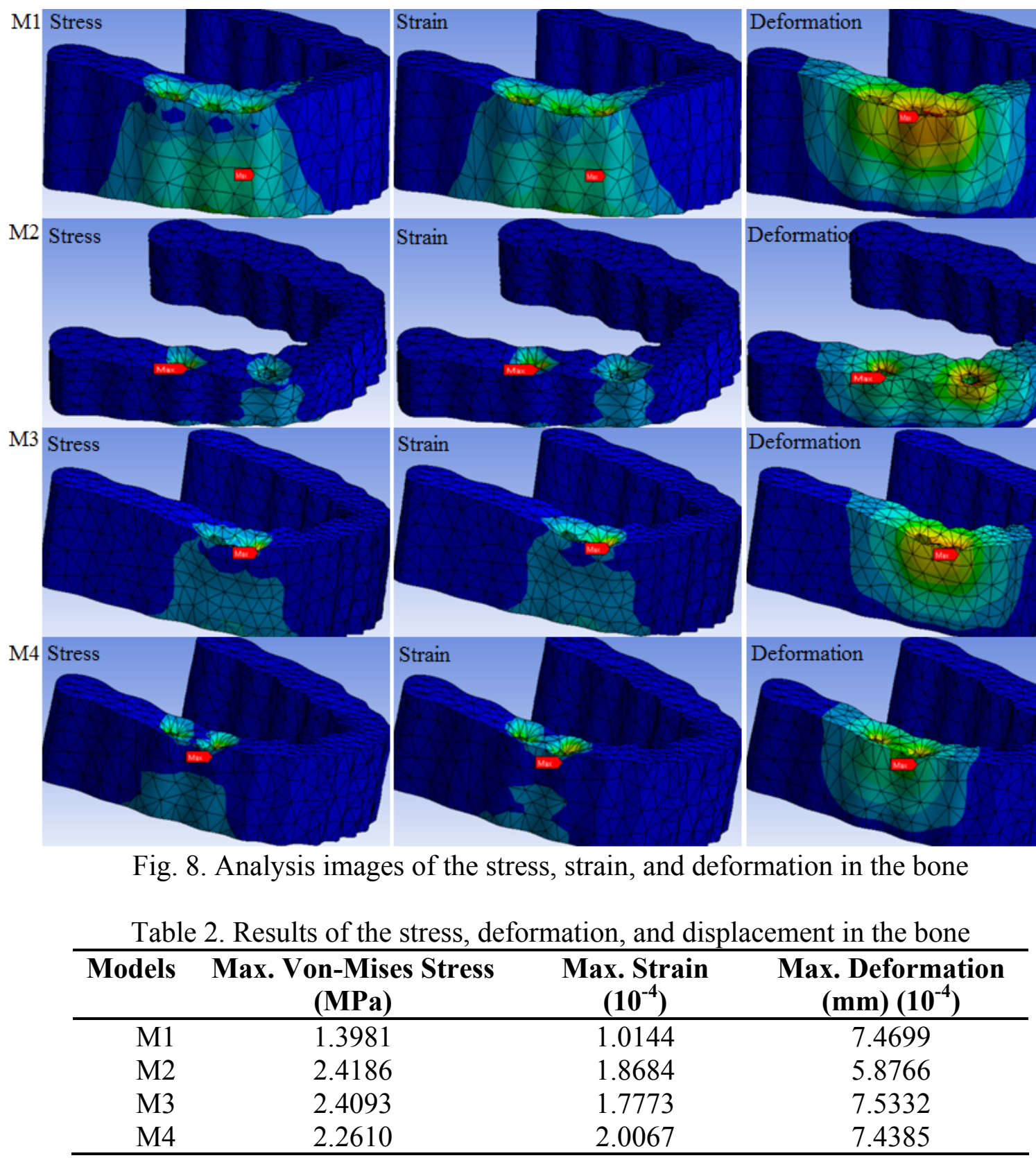

The stress, strain, and displacement images and numerical values of the analysis results for the dental implants are shown in Figure 9 and Table 3, respectively. As can be seen from the table, the highest stress values for the first, second, and third dental implants were obtained in the M1, M4 and M4 respectively. The highest strain values for the first, second, and third dental implants were obtained in the M1, M4, and M4. The highest deformation values for the first, second, and third dental implants were obtained in the M3, M4, and M4. As can be seen from the table, the lowest stress values for the first, second, and third dental implants were obtained in the M2, M1 and M1 respectively. The lowest strain values for the first, second, and third dental implants were obtained in the M2, M1, and M1. The lowest deformation values for the first, second, third dental implants were obtained in the M2, M3, and M1. 


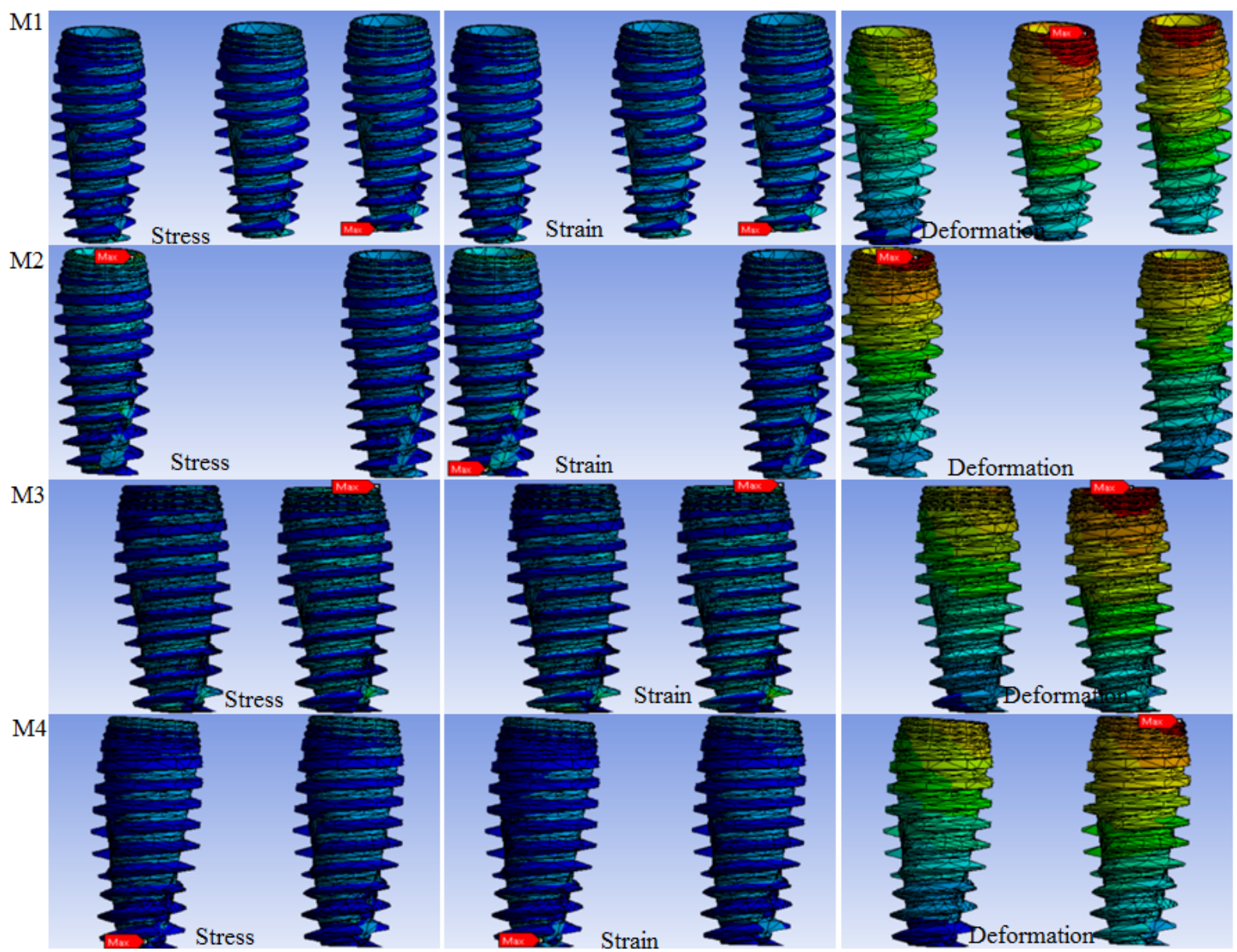

Fig. 9. Stresses, strains and deformations in the dental implants

Table 3. Results of the stress, deformation, and displacement in the implants

\begin{tabular}{|c|c|c|c|}
\hline \multicolumn{4}{|c|}{ First Dental Implant } \\
\hline Models & $\begin{array}{c}\text { Max. Von-Mises Stress } \\
\text { (MPa) }\end{array}$ & $\begin{array}{c}\text { Max. Strain } \\
\left(10^{-4}\right)\end{array}$ & $\begin{array}{l}\text { Max. Deformation } \\
(\mathbf{m m})\left(10^{-4}\right)\end{array}$ \\
\hline M1 & 16.7090 & 1.5345 & 7.0567 \\
\hline M2 & 7.0089 & 0.6488 & 5.4778 \\
\hline M3 & 16.3770 & 1.4900 & 7.8450 \\
\hline M4 & - & - & - \\
\hline \multicolumn{4}{|c|}{ Second Dental Implant } \\
\hline Models & $\begin{array}{c}\text { Max. Von-Mises Stress } \\
\text { (MPa) }\end{array}$ & $\begin{array}{c}\text { Max. Strain } \\
\left(10^{-4}\right)\end{array}$ & $\begin{array}{l}\text { Max. Deformation } \\
(\mathrm{mm})\left(\mathbf{1 0}^{-4}\right)\end{array}$ \\
\hline M1 & 8.8032 & 0.8147 & 7.3773 \\
\hline M2 & - & - & - \\
\hline M3 & 14.0200 & 1.3748 & 6.8087 \\
\hline M4 & 15.9690 & 1.5023 & 7.5063 \\
\hline \multicolumn{4}{|c|}{ Third Dental Implant } \\
\hline Models & $\begin{array}{c}\text { Max. Von-Mises Stress } \\
(\mathrm{MPa})\end{array}$ & $\begin{array}{c}\text { Max. Strain } \\
\left(10^{-4}\right)\end{array}$ & $\begin{array}{l}\text { Max. Deformation } \\
(\mathrm{mm})\left(1^{-4}\right)\end{array}$ \\
\hline M1 & 9.6161 & 0.9130 & 6.1572 \\
\hline M2 & 17.0410 & 1.7195 & 6.1651 \\
\hline M3 & - & - & - \\
\hline M4 & 26.7020 & 2.6432 & 6.5491 \\
\hline
\end{tabular}


The stress, strain and displacement images and numerical values of the analysis results for the abutment are shown in Figure 10 and Table 4, respectively. As can be seen from the table, the highest stress values for the first, second, and third abutments were obtained in the M1, M4, and M4 respectively. The highest strain values for the first, second, and third abutments were obtained in the M1, M4, and M4. The highest deformation values for the first, second, and third abutments were obtained in the M3, M4, and M4. As can be seen from the table, the lowest stress values for the first, second, and third abutments were obtained in the M3, M3, and M1 respectively. The highest strain values for the first, second, and third abutments were obtained in the M3, M3, and M1. The highest deformation values for the first, second, and third abutments were obtained in the M2, M3, and M1.

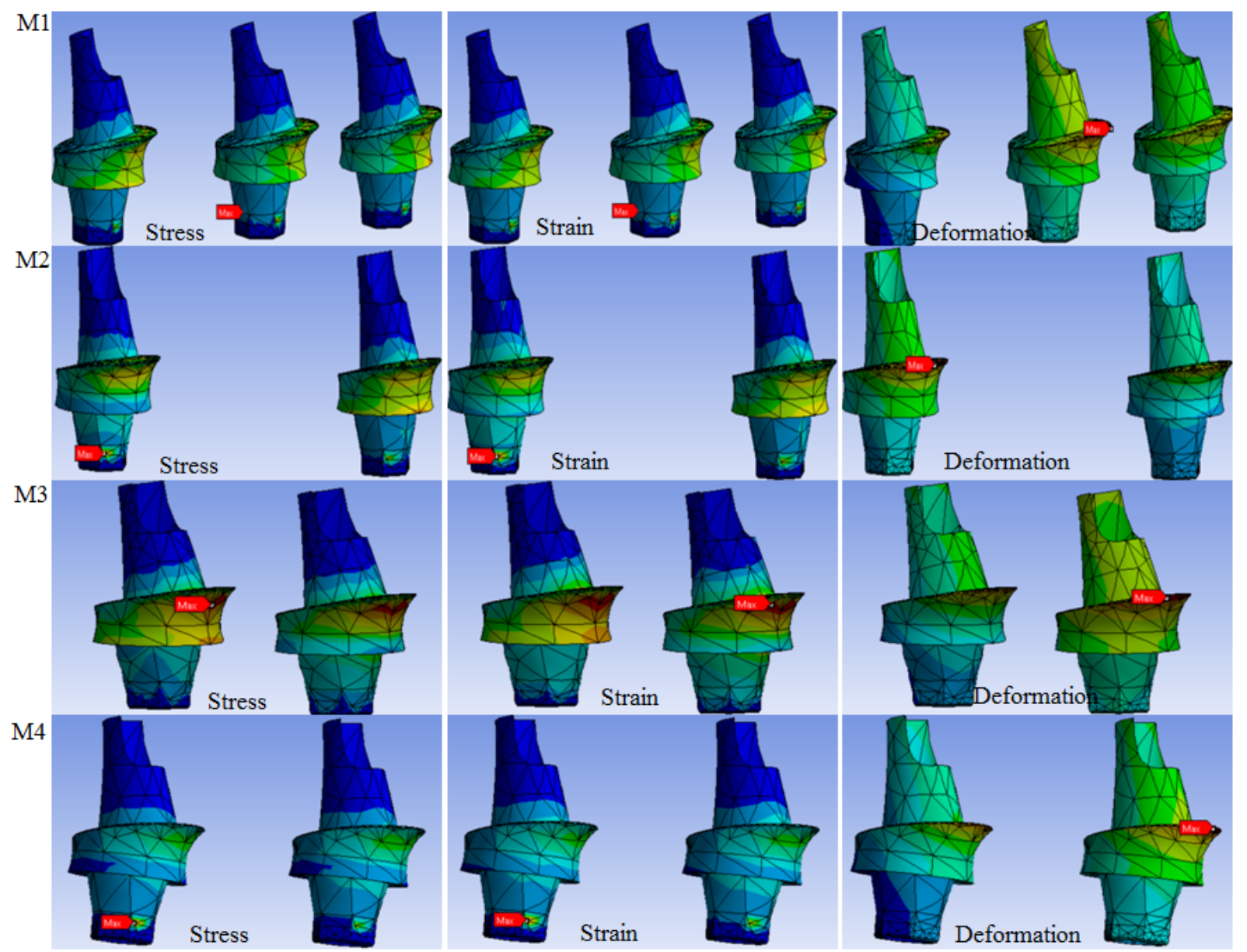

Fig. 10. Stresses, strains, and deformations in the abutments 
Table 4. Results of the stress, deformation, and displacement in the abutments

\section{First Dental Implant}

\begin{tabular}{|c|c|c|c|}
\hline Models & $\begin{array}{c}\text { Max. Von-Mises Stress } \\
\text { (MPa) }\end{array}$ & $\begin{array}{c}\text { Max. Strain } \\
\left(10^{-4}\right)\end{array}$ & $\begin{array}{l}\text { Max. Deformation } \\
(\mathrm{mm})\left(10^{-4}\right)\end{array}$ \\
\hline M1 & 11.1670 & 1.1098 & 9.5823 \\
\hline M2 & 10.2530 & 0.9523 & 8.3830 \\
\hline M3 & 9.2542 & 0.8634 & 11.0920 \\
\hline M4 & - & - & - \\
\hline \multicolumn{4}{|c|}{ Second Dental Implant } \\
\hline Models & $\begin{array}{c}\begin{array}{c}\text { Max. Von-Mises Stress } \\
(\mathrm{MPa})\end{array} \\
\end{array}$ & $\begin{array}{c}\text { Max. Strain } \\
\left(10^{-4}\right)\end{array}$ & $\begin{array}{c}\text { Max. Deformation } \\
(\mathrm{mm})\left(10^{-4}\right)\end{array}$ \\
\hline M1 & 11.9320 & 1.1721 & 10.6140 \\
\hline M2 & - & - & - \\
\hline M3 & 9.2966 & 0.8609 & 10.1660 \\
\hline M4 & 12.5810 & 1.2684 & 10.6880 \\
\hline \multicolumn{4}{|c|}{ Third Dental Implant } \\
\hline Models & $\begin{array}{c}\text { Max. Von-Mises Stress } \\
(\mathrm{MPa})\end{array}$ & $\begin{array}{c}\text { Max. Strain } \\
\left(10^{-4}\right)\end{array}$ & $\begin{array}{l}\text { Max. Deformation } \\
(\mathrm{mm})\left(\mathbf{1 0}^{-4}\right)\end{array}$ \\
\hline M1 & 10.5810 & 1.0424 & 9.4376 \\
\hline M2 & 12.0060 & 1.1913 & 9.5851 \\
\hline M3 & - & - & - \\
\hline M4 & 17.6070 & 1.7118 & 10.0410 \\
\hline
\end{tabular}

According to Figures 11-13, it is seen that the stress values of bone are close to each other for M1, M2, M3 and M4 models, but it has a lower value when using M1. In dental implants, the stress values are found different for the first, second and third dental implants in all models. The stress values in the first and third dental implant are higher than the second implant. The stress values for abutments are close to each other for all models. Maximum Von-Mises stress values for all abutments were obtained when using M4, while minimum stresses were obtained when using M2.

As can also be seen from the data in Figures 11-13, the highest value of strain in bone and dental implants was obtained when using M4, and the lowest value of strain was obtained when using M1. The maximum strain values for the abutments were obtained when Model 4 was used as the design.

When the numerical data in Figures 11-13 are examined, it is seen that the results obtained using M1, M2, M3, and M4 designs were close to each other. The maximum deformation values were obtained when using M3 in bone, dental implants and abutments, while the lowest values were obtained in M2.

When all the results were examined, the lowest stress, strain and deformation results among the analyzed design were generally seen in the M1. As a result, it is possible to say that the most suitable model among these for models is the M1. 

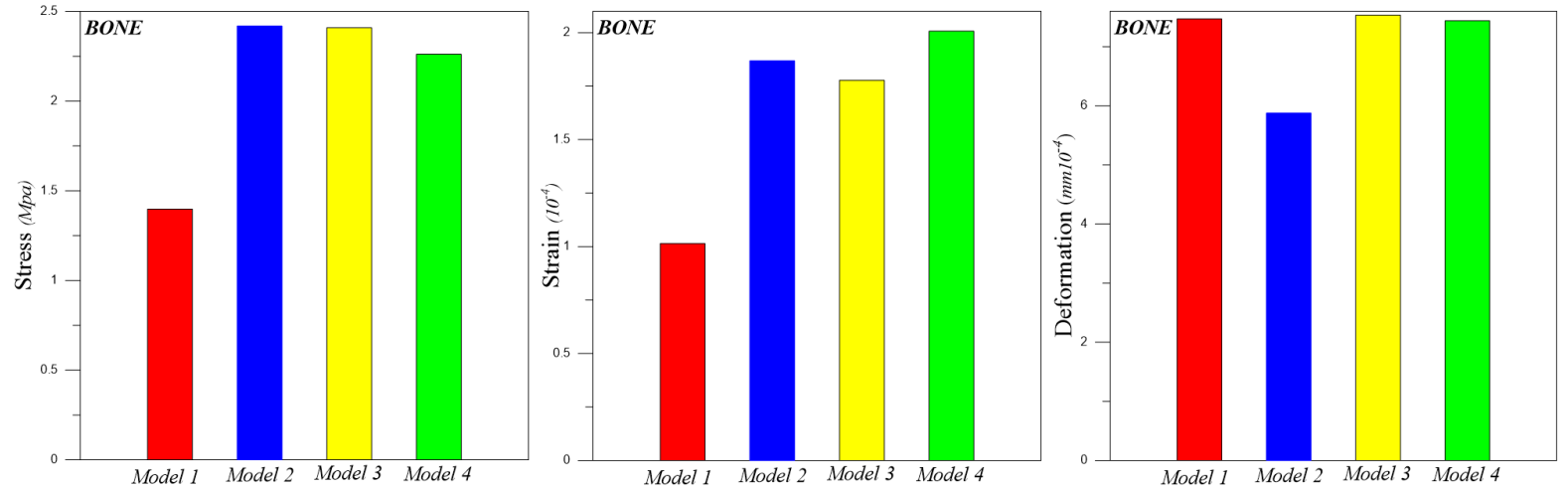

Fig. 11. Stresses, strains, and deformations in the bone
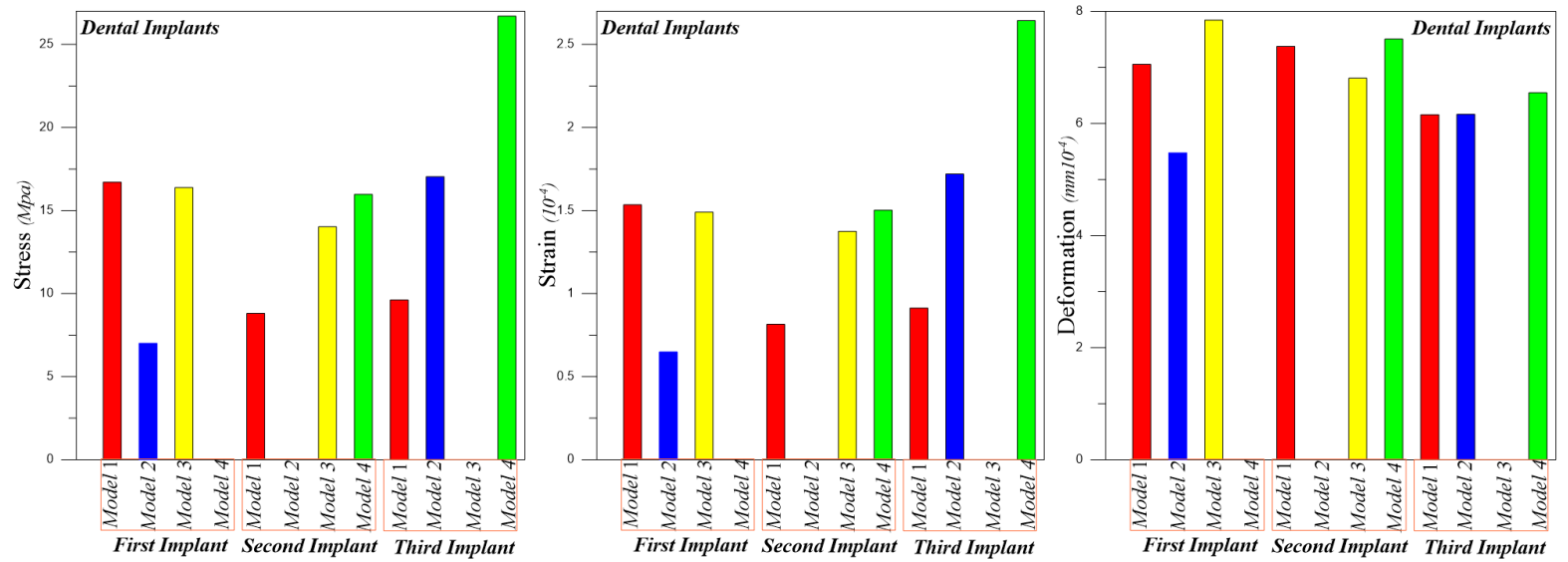

Fig. 12. Stresses, strains, and deformations in the dental implants
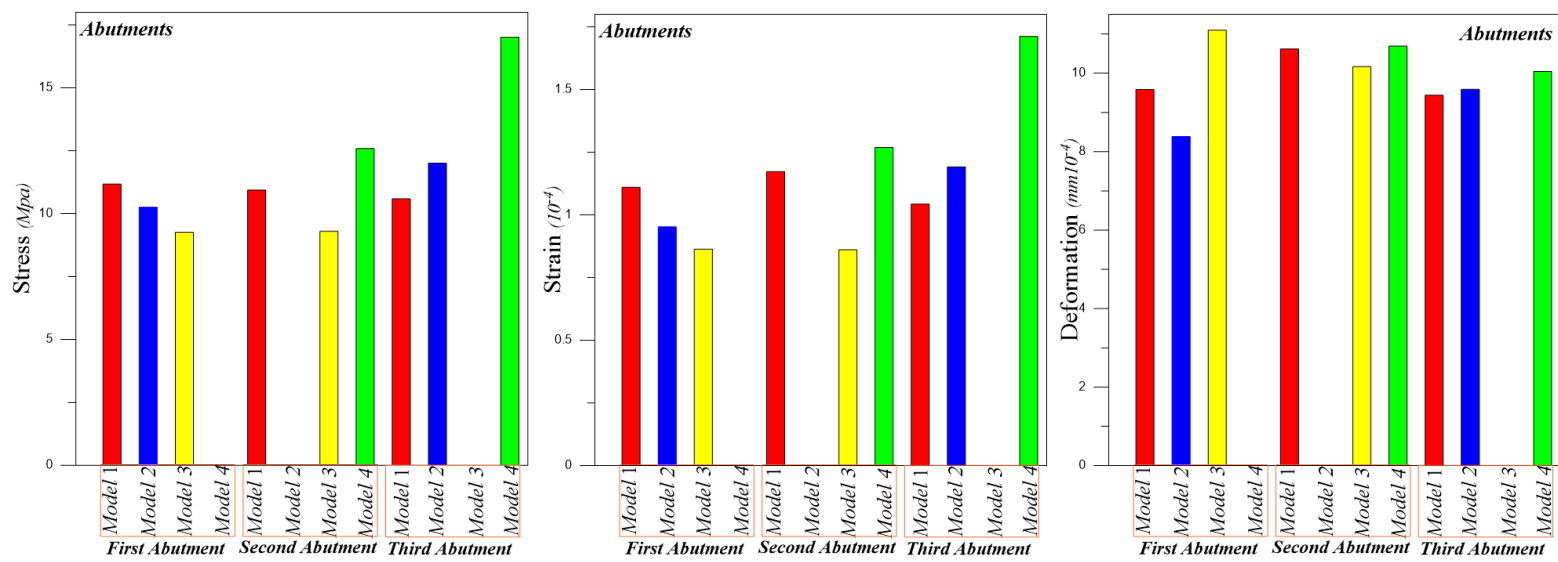

Fig. 13. Stresses, strains, and deformations in the abutments

\section{Conclusion}

In the study, the stress, strain and deformation that were formed as a result of supporting dental implant supported prostheses with three and two implants in different locations and with a single type of implant material were examined. Three models with two implants and one model with three implants were created as a dental implant layout. The obtained models are analyzed 
with the help of the ANSYS Workbench finite element program. The results are described below.

1. The stress values occurring in three implant models were lower than the two implant models for all loading conditions. The reason for this may be that the applied force is shared by three implants.

2. The maximum Von-Mises stress, strain and deformation values occurring in two implant models differed by the change in the region of the implant location and the applied load. For example, in Model 2, maximum stress, strain and deformation results are from the application of the load to the first molars, whereas in Model 3, the first molar tooth is in the first molar tooth, while in Model 4 the stress and strain values are in the first molar tooth. The replacement value was observed to occur in the second premolar tooth.

3. The stresses occurring in the implants are concentrated in the implant neck region and reached the highest strain values at the implant neck point. The channels located in the implant neck region and which allow the implant to fit better in the bone caused the initial loading to be covered by the implant neck region and the region where the maximum stress values were observed.

4. The stresses, deformations, and total displacements occurring in the abutments are concentrated in the abutment step region and the highest values are also formed in this region.

5 . When the stress values occurring in the bone were examined, the highest values occurred in the hard bone layer.

6. Decrease in the number of implants caused negative biomechanical behavior for all structures (M2, M3, M4).

7. Considering two implant-supported prostheses, Model 2 showed that stress and strain distributions were more suitable.

8. The use of fixed showed unwanted biomechanical behavior for M3 and M4, mainly for M4.

9. The use of three implants gave lower results of stress and strain.

10. Considering two implant-supported prostheses, M3 and M4 showed unwanted biomechanical behavior, especially for M4.

\section{References}

[1] Uzun, B. and Civalek, O., Nonlocal FEM formulation for vibration analysis of nanowires on elastic matrix with different materials, Mathematical and Computational Applications, 24, 38, 2019.

[2] Jalaei, M. and Civalek, Ö., On dynamic instability of magnetically embedded viscoelastic porous FG nanobeam, International Journal of Engineering Science, 143, 14-32, 2019.

[3] Civalek, O., Uzun, B., Yayl, M.O. and Akgöz, B., Size-dependent transverse and longitudinal vibrations of embedded carbon and silica carbide nanotubes by nonlocal finite element method, European Physical Journal Plus, 135, 381, 2020.

[4] Civalek, Ö. and Demir, C., A simple mathematical model of microtubules surrounded by an elastic matrix by nonlocal finite element method, Applied Mathematics and Computation, 289, 335-352, 2016.

[5] Gurses, M., Akgoz, B. and Civalek, O., Mathematical modeling of vibration problem of nanosized annular sector plates using the nonlocal continuum theory via eight-node discrete singular convolution transformation, Applied Mathematics and Computation, 219, 3226- 3240, 2012.

[6] Yaylaci, M. and Avcar, M., Finite element modeling of contact between an elastic layer and two elastic quarter planes, Computers and Concrete, 26(2), 107-114, 2020. 
[7] Yaylaci, M., Terzi, C. and Avcar, M., Numerical analysis of the receding contact problem of two bonded layers resting on an elastic half plane, Structural Engineering and Mechanics, 72(6), 775-783, 2019.

[8] Yaylacı, M., Bayrak, M.Ç. and Avcar, M., Finite element modeling of receding contact problem, International Journal of Engineering and Applied Sciences, 11(4) 468-475, 2019.

[9] Chen, J., Ahmad, R., Suenaga, H., Li W., Swain, M. and Li Q., A comparative study on complete and implant retained denture treatments - A biomechanics perspective, Journal of Biomechanics, 48(3), 512-519, 2015. https://doi.org/10.1016/j.jbiomech.2014.11.043.

[10] Van Osterwyck, H., Duyck, J., Vander, S., Vander, P.G., Decoomans, M., Lieven, S., Puers, R. and Naert, L., The influence of bone mechanical properties and implant fixation upon bone loading around oral implants, Clin Oral Implants Res, 9(6), 407-412, 1998. https://doi.org/10.1034/j.1600-0501.1996.090606.x

[11] Geng, J.P., Tan, K.B. and Liu, G.R., Application of finite element analysis in implant dentistry: a review of the literature, Journal of Prosthetic Dentistry, 85(6), 585-98, 2001. https://doi.org/ 10.1067/mpr.2001.115251.

[12] Kunavisarut, C., Lisa, A.. Lang, L.A., Stoner, B.R. and Felton, D.A., Finite element analysis on dental implant- supported prostheses without passive fit, Journal of Prosthodontics, 11(1), 30-40, 2002. https://doi.org/ 10.1111/j.1532-849x.2002.00030.x.

[13] Ding, X., Zhu, X.H., Liao, S.H., Zhang, X.H. and Chen, H., Implant-Bone interface stress distribution in immediately loaded implants of different diameters: a three-dimensional finite element analysis, Journal of Prosthodontics, 18, 393-402, 2009. https://doi.org/ 10.1111/j.1532-849X.2009.00453.x.

[14] Hsu, M.L. and Chang, C.L., Application of finite element analysis in dentistry, Finite Element Analysis, 5, 43-6, 2010.

[15] Kumar, G.A., Kovoor, L.C. and Oommen, V.M., Three-dimensional finite element analysis of the stress distribution around the implant and tooth in tooth implant- supported fixed prosthesis designs, Journal of Dental Implants, 1(2), 75-79, 2011.

[16] El-Anwar, M.I. and El-Zawahry, M.M., A three-dimensional finite element study on dental implant design, Journal of Genetic Engineering and Biotechnology, 9(1), 77-82, 2011. https://doi.org/10.1016/j.jgeb.2011.05.007.

[17] Baggi, L., Pastore, S., Girolamo, M.D. and Vairo, G., Implant-bone load transfer mechanisms in complete-arch prostheses supported by four implants: A three-dimensional finite element approach, The Journal of Prosthetic Dentistry, 109(1), 9-21, 2013.

[18] Liu, J., Pan, S., Dong, J., Mob, Z., Fan, Y. and Feng, H., Influence of implant number on the biomechanical behavior of mandibular implant-retained / supported overdentures: A three-dimensional finite element analysis, Journal of Dentistry, 41, 241-249, 2013.

[19] Cicciu, M., Bramanti, E., Cecchetti, F., Scappaticci, L., Guglielmino, E. and Risitano, G., FEM and Von Mises analyses of different dental implant shapes for masticator loading distribution, Oral\&Implantology, 1, 1-10, 2014.

[20] Hambli, R., 3D finite element simulation of human proximal femoral fracture under quasistatic load, Biomaterials and Biomechanics in Bioengineering, 1(4), 175-188, 2016. http://dx.doi.org/10.12989/bme.2014.1.4.175.

[21] Parkhe, N., Hambire, U., Hambire, C. and Gosavi, S., Enhancing dental implant model by evaluation of three-dimensional finite element analysis, International Journal of Engineering Science Invention, 4(12), 26-33, 2015.

[22] Gonzalez, F.J.Q. and Nuno, N., Finite element modeling of manufacturing irregularities of porous materials, Biomaterials and Biomechanics in Bioengineering, 3(1), 1-14, 2016. https://doi.org/10.12989/BME.2016.3.1.001. 
[23] Mahajan, S. and Patil, R., Application of finite element analysis to optimizing dental implant, International Research Journal of Engineering and Technology, 3(2), 850-856, 2016.

[24] Razaghi, R., Mallakzadeh, M. and Haghpanahi, M., Dynamic simulation and finite element analysis of the maxillary bone injury around dental implant. biomedical engineering: applications, Basis and Communications, 28(2), 1-10, 2016.

[25] Demenko, V., Linetskiy, I., Linetska, L., Nesvit, V., Shevchenko, A., Yefremov, O. and Weisskircher, H.W., Prognosis of implant longevity in terms of annual bone loss: a methodological finite element study, Computer Methods in Biomechanics and Biomedical Engineering, 19(2), 180-187, 2016. https://doi.org/ 10.1080/10255842.2015.1005079.

[26] Macedo, J.P., Pereira, J., Faria, J., C.A. Pereira, J., Alves, L., Henriques, B., Souza, J.C.M. and López-López, J., Finite element analysis of stress extent at peri-implant bone surrounding external hexagon or Morse taper implant, Journal of the Mechanical Behavior of Biomedical Materials, 71, 441-447, 2017. https://doi.org/ 10.1016/j.jmbbm.2017.03.011.

[27] Aumnakmanee, S., Yodpiji, N., Jantong, N. and Jongprasithporn, M., Finite element analysis of dental implant prosthetic, Materials Today: Proceedings, 5, 9525-9534, 2018. https://doi.org/10.1016/j.matpr.2017.10.134.

[28] Jafarian, M., Mirhashemi, F.S. and Emadi, N., Finite element analysis of stress distribution around a dental implant with different amounts of bone loss: An in vitro study, Dental and Medical Problems, 56(1), 27-32, 2019. https://doi.org/ 10.17219/dmp/102710.

[29] Wu, A.Y.J., Hsu, J.T., Fuh, L.J. and Huang, H.L., Biomechanical effect of implant design on four implants supporting mandibular full-arch fixed dentures: In vitro test and finite element analysis, Journal of the Formosan Medical Association, 4, 1-10, 2019. https://doi.org/ 10.1016/j.jfma.2019.12.001.

[30] Jimenez, V.J.F., Burgueno-Barris, G., Gomez-Gonzalez, S., Lopez-Lopez, J., ValmasedaCastellon, E. and Fernandez-Aguado. E., Finite element analysis of narrow dental implants, Dental Materials, 36(7), 927-935, 2020.

[31] Robau Porrua, A., Perez Rodriquez, Y., Soris Rodriquez, L.M. and Perez Acosta, O., The effect of diameter, length and elastic modulus of a dental implants on stress and strain levels in peri-implant bone: A 3D finite element analysis, Bio-Medical Materials and Engineering, 30, 541-558, 2020. https://doi.org/ 10.3233/bme-191073.

[32] Zhong, J., Guazzato, M., Chen, J., Zhang, Z., Sun, G., Huo, X., Liu, X., Ahmad, R. and Li, Q., Effect of different implant configurations on biomechanical behavior of full-arch implant-supported mandibular monolithic zirconia fixed prostheses, Journal of the Mechanical Behavior of Biomedical Materials, 102, 1-10, 2020. https://doi.org/ 10.1016/j.jmbbm.2019.103490.

[33] Terzi, M., Güvercin, Y., Ateş, S.M., Sekban, D.M. and Yaylacı M., Effect of different abutment materials on stress distribution in peripheral bone and dental implant system, Sigma Journal of Engineering and Natural Sciences, 38(3), 1495-1507, 2020.

[34] Solidworks 2018, (2018). Dassault Systèmes Solidworks Corporation. Waltham MA, USA.

[35] ANSYS 16.0, (2016). Swanson Analysis Systems Inc., Houston PA, USA.

[36] Wadatkar, N.D., Londhe, S.D. and Metkar R.M., Stress analysis of fractured femur bone and implant of different metallic biomaterials, Trends in Biomaterials and Artificial Organs, 34(3), 96-99, 2020.

[37] Korkmaz, H.H., Evaluation of different miniplates in fxation of fractured human mandible with the finite element method, Oral Surg Oral Med Oral Path Oral Radiol Endod, 103(6), $1-13,2007$. 